by-pass operations to prove their method is far superior to conservative management. The reader must be reminded that the patients in this study were studied at random and had not been under the constant surveillance of the author since time of injury.

Two patients had kidney stones. One who had been on a suprapubic catheter from a birth injury until I9 years of age was found to have a stone in the lower calyx of the right kidney. Another patient who was 35 years of age and had been injured at the age of 15 had had stones removed once on the right and twice on the left kidney.

One patient with a complete lesion at thoracic 4 and an upper motor neuron bladder was injured at age $\mathrm{I} \frac{1}{2}$ and at the time of examination, age $\mathrm{I} 4$, his kidneys were normal bilaterally. He had never been on a catheter and when he was seven years of age he had been able to use an external appliance. His reflex bladder at birth has persisted till time of examination-I4.

Only one of these patients had ischial ulcers. These were not due to poor hygiene but rather to trauma following a fall when the patient fell on to the ischial sites.

\title{
SUMMARY
}

The excretory pyelograms of 28 patients who had sustained spinal cord injuries during childhood were studied at random. They had not been managed entirely at the author's clinics. The age at injury ranged from birth to 15 years. The period of injury ranged from six weeks to 35 years. Thirty-eight (68 per cent.) of the 56 kidneys were normal. Seventeen (6I per cent.) of the 28 patients had normal kidneys bilaterally. Eleven ( 39 per cent.) of the 28 patients had pathology in one or both of the kidneys; only two patients had a single kidney which was considered 'poor'.

\section{CONSERVATIVE MANAGEMENT OF THE URINARY BLADDER IN MYELODYSPLASIA}

\section{A. Estin Comarr, M.D.}

THIS communication's purpose is to present the results of excretory pyelography among patients with myelodysplasia who have not been treated with by-pass operations such as ileal conduits (Bricker operation) or cutaneous vesicostomies. These patients were seen in clinics by this investigator at random and each was given a neuro-urological examination. The excretory pyelograms performed shortly before the examination were interpreted and the findings recorded.

\section{METHOD AND MATERIAL}

Each kidney of the intravenous pyelogram was graded from 0 to 3; 0 indicating an essentially normal kidney. Grades I to 3 represented degrees of pathology, ranging from Grade I which indicated blunting of the calices to Grade 3 which indicated gross hydronephrosis, non-functioning nephrectomy, or atrophy. 
Forty-six patients, 27 male, I9 female, were studied with ages ranging from five months to 37 years (Table I). Twenty-five had complete lesions, I 4 incomplete, and seven patients were difficult to classify. External rectal sphincter tone was present in five patients and one had volitional control of the external sphincter. Forty-one patients did not have external rectal sphincter tone. Thirteen patients had positive ice-water tests, of which I I voided by extrinsic pressure and only two voided by detrusor contraction. These two patients did not have external rectal sphincter tone. In I 5 patients the tests proved negative and the remainder did not have the tests performed for a variety of reasons.

TABLE I

Age Range

\begin{tabular}{|c|c|c|c|c|c|}
\hline Age & $\begin{array}{c}\text { No. of } \\
\text { patients }\end{array}$ & Age & $\begin{array}{c}\text { No. of } \\
\text { patients }\end{array}$ & Age & $\begin{array}{c}\text { No. of } \\
\text { patients }\end{array}$ \\
\hline $55 \mathrm{M}$ & I & I0 Y & 4 & I8 Y & I \\
\hline $8 \mathrm{M}$ & I & I I Y & 4 & 19 Y & I \\
$2 \mathrm{Y}$ & 2 & I3 Y & 3 & $20 \mathrm{Y}$ & 3 \\
$4 \mathrm{Y}$ & 4 & I4 Y & 2 & 2 I Y & 3 \\
$6 \mathrm{Y}$ & 3 & I5 Y & I & $34 \mathrm{Y}$ & I \\
$7 \mathrm{Y}$ & 2 & I6 Y & 2 & $35 \mathrm{Y}$ & I \\
$8 \mathrm{Y}$ & 2 & I7 Y & 3 & $37 \mathrm{Y}$ & I \\
$9 \mathrm{Y}$ & I & & & \\
\hline
\end{tabular}

Key to Tables
$\mathbf{M}=$ Months.
$\mathrm{Y}=$ Years.
Ext. appl. = External appliance.
N.F. $=$ Non-function.
I.C. = Intermittent catheterisation.
Ectomy $=$ Nephrectomy.
$\mathrm{R}=$ Right.
$\mathrm{f}=$ Female.
$\mathrm{I}=\mathrm{Left}$
$\mathrm{m}=$ Male.
$\mathrm{c}=$ Catheter.
$\mathrm{d}=$ Diapers.

\section{RESULTS}

Thirty-two, I 8 males, I 4 females (70 per cent.) of the 46 patients had normal kidneys. Sixty-four (70 per cent.) out of 92 kidneys were normal. Table II shows the patients: age, range, gender, and evacuation method of the bladder contents among patients with bilaterally normal kidneys.

Fourteen ( 30 per cent.) patients showed some degree of pathology in one or other kidney and among these five ( 18 per cent.) showed normal kidneys. Table III shows the age range of the patients, the gender, and method of evacuation of the bladder contents among the patients who showed some degree of pathology unilaterally or bilaterally.

\section{DISCUSSION}

It is not the purpose of this investigation to discuss the pros and cons of conservative management versus ileal conduit or other by-pass proceedures. 
Rather, the results of the study are made available for use as a comparison with different methods of therapy. A review of other proceedures is presented elsewhere (Morales et al., 1956; Morales, 1967; Bors et al., I971; Lorber, 1971).

TABLE II

Normal Kidneys Bilaterally (32 Patients)

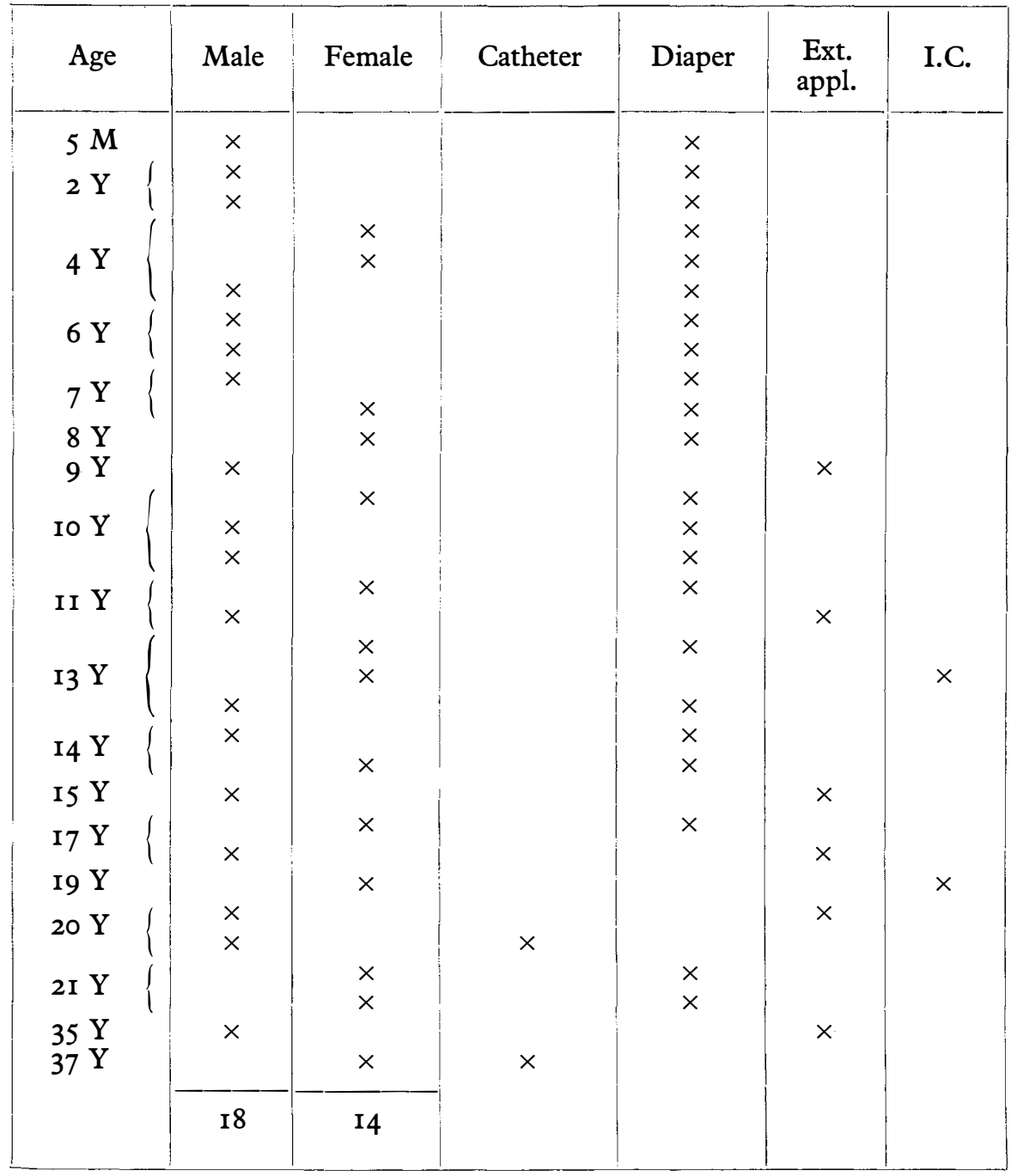

Abbreviations as in Table I.

This writer has always treated his congenital neurogenic bladders as he has adults with neurogenic bladders (Comarr, I959, I964, I965, I969).

Seventy per cent. of the patients in this series had bilaterally normal kidneys; 75 per cent. (69) of the 92 kidneys were normal. Of the 30 per cent. of patients who had some degree of pathology in the kidneys there was one patient with bilateral 
hydronephrosis; one with a unilateral hydronephrosis; one a unilateral non-function; one a unilateral nephrectomy; one a unilateral atrophy; one a bilateral Grade 2 and the others had pathology of minor magnitude.

It is reiterated that this was an 'at random study', had these patients been carefully observed with routine periodic urological examinations (Morales et al., 1956; Morales, 1967), the more severe grades of pathology may have been averted.

Two patients had reached 35 and 37 years of age, respectively, with essentially normally functioning kidneys (Table II). The 37-year-old patient was a female who for the first 25 years of her life had been in diapers and in the following 12 years on a catheter. The 35-year-old patient, male, had been in diapers until such time as the size of his penis could retain an external appliance; this is the usual situation for all males whose bladders become balanced. Females whose bladders

TABLE III

Pathology in One or Both Kidneys (I4 Patients)

\begin{tabular}{|c|c|c|c|c|c|c|c|c|c|}
\hline Age & $\begin{array}{c}\text { R-L } \\
\text { O-I }\end{array}$ & $\begin{array}{c}\text { R-L } \\
\text { I-O }\end{array}$ & $\begin{array}{c}\text { R-L } \\
0-3\end{array}$ & O-N.F. & O-Ectomy & I-I & Atrophy-I & $2-2$ & $3-3$ \\
\hline $8 M$ & - & - & - & - & I (md) & - & - & - & - \\
\hline $4 Y$ & - & - & - & - & - & - & - & I (fd) & - \\
\hline $6 \mathrm{Y}$ & - & - & - & I (fd) & - & - & - & - & - \\
\hline $8 \mathrm{Y}$ & 一 & - & I (fd) & - & - & - & - & - & - \\
\hline Io $\mathrm{Y}$ & - & - & - & - & - & I (md) & - & - & - \\
\hline II $\mathrm{Y}$ & 一 & I (fd) & - & - & - & I (fd) & - & - & - \\
\hline I6 Y & - & - & - & - & - & - & I (mc) & I $(\mathrm{mc})$ & - \\
\hline I7 Y & - & - & - & - & - & - & - & I (mc) & - \\
\hline I8 Y & - & - & - & - & - & - & - & - & I (me) \\
\hline $20 \mathrm{Y}$ & $\mathrm{I}(\mathrm{mc})$ & - & - & - & - & - & - & - & - \\
\hline $2 \mathrm{I} \mathrm{Y}$ & - & - & - & - & - & I (me) & - & - & - \\
\hline $34 \mathrm{Y}$ & - & - & - & - & - & I $(\mathrm{mc})$ & - & - & - \\
\hline Totals & I & I & I & I & I & 4 & I & 3 & I \\
\hline
\end{tabular}

Abbreviations as in Table I.

become balanced use diapers and plastic panties for the rest of their lives. One 34-year-old male patient had always used a catheter, his renal pathology was only Grade I bilaterally (Table III).

Decubitus ulcers were not a great complication in this group. The physician in care of these patients must, from the onset, indoctrinate the parents to the importance of good skin hygiene.

Two females, one aged I3 years and the other a I9-year-old college student, have carried out self-intermittent catheterisation for many years without incontinence of urine between catheterisations.

\section{SUMMARY}

In an 'at random study', 70 per cent. of 46 patients treated conservatively (without by-pass operations) revealed normal excretory pyelograms. Seventy-five 
per cent. of 92 kidneys were normal. The ages of these myelodysplasia patients ranged from five months to 37 years. A plea is made for continuous life-time periodic urological examinations of these patients.

\section{REFERENCES}

Bors, E. \& Comarr, A. E. (I97I). Neurological-urology. Basel: S. Karger.

ComARR, A. E. (I959). The practical urological management of the patient with spinal cord injury. British fournal of Urology, 31, I-46.

ComarR, A. E. (I969). Special considerations of the early management of the paralyzed bladder. Fournal of the Indian Medical Profession, 16, 7235-7240.

ComARR, A. E. Intermittent catheterization for the traumatic cord bladder. Fournal of Urology, awaiting publication.

Comarr, A. E. (I964). Neurogenic bladder. Paraplegia, 2, I25-I3I.

ComarR, A. E. (I965). Management of the traumatic cord bladder. Urologia Internationalis, 20, I-I I.

LoRBER, L. (I97I). Results of treatment of myelomeningocele. Develop. Med. Child Neurol. 13, 279-303.

Morales, P. A., Deaver, G. G. \& Hotchriss, R. S. (1956). Urological complications of spina bifida in children. Fournal of Urology, 75, 537-550.

MoRALES, P. A. (1967). Urinary problems in children with myelomeningocele. Archives of Physical Medicine and Rehabilitation, 48, 402-409. 